\title{
The Psoriasis Therapeutic Potential of a Novel Short Laminin Peptide C16
}

\author{
Tsung-Chuan Ho ${ }^{1}$, Shu-I Yeh ${ }^{2}$, Show-Li Chen ${ }^{3}$ and Yeou-Ping Tsao ${ }^{1,2, *}$ \\ 1 Department of Medical Research, Mackay Memorial Hospital, No. 45, Minsheng Rd., Tamsui District, \\ New Taipei City 25160, Taiwan \\ 2 Department of Ophthalmology, Mackay Memorial Hospital, No. 92, Sec. 2, Chung Shan North Road, \\ Taipei 10449, Taiwan \\ 3 Graduate Institute of Microbiology, College of Medicine, National Taiwan University, 7F, No. 1, Sec. 1, \\ Jen-Ai Rd., Taipei 10617, Taiwan \\ * Correspondence: yptsao@yahoo.com; Tel.: +886-2-28094661 (ext. 3076)
}

Received: 17 June 2019; Accepted: 25 June 2019; Published: 27 June 2019

\begin{abstract}
Psoriasis is a chronic inflammatory skin disease characterized by excessive growth of keratinocytes and hyperkeratosis in the epidermis. An abnormality of the non-lesional epidermis at an early stage of psoriasis is involved in triggering inflammatory cell infiltration into the dermis. Integrin $\alpha 5 \beta 1$ acts as a receptor for fibronectin and has been found to be overexpressed in non-lesional psoriatic epidermis. To investigate whether $\alpha 5 \beta 1$ integrin has a potential as a drug target for psoriasis treatment, the $\alpha 5 \beta 1$ integrin-binding peptide, C16, was used to obstruct the HaCat keratinocyte cellular responses induced by fibronectin (Fn) in culture and psoriasis-like skin inflammation induced in mice by imiquimod (IMQ). The C16 exhibited antagonistic activity against $\alpha 5 \beta 1$ integrin in HaCat cells, with evidence of suppression of the Fn-mediated proliferative, cytoskeletal, and inflammatory responses. Topical treatment with $\mathrm{C} 16$ greatly reduced the IMQ-induced epidermal hyperplasia, infiltration of neutrophils/macrophages, and expression of pro-inflammatory mediators in mouse skin. The C16SP (C16-derived short peptide; DITYVRLKF) also exhibited antagonistic activity, suppressing $\alpha 5 \beta 1$ integrin activity in culture, and reducing IMQ-induced skin inflammation. Taken together, this study provides the first evidence that $\alpha 5 \beta 1$ integrin may be a potential drug target for psoriasis. The synthetic $\mathrm{C} 16$ peptide may serve as an agent for psoriasis therapy.
\end{abstract}

Keywords: psoriasis; C16 peptide; $\alpha 5 \beta 1$ integrin; fibronectin; inflammation

\section{Introduction}

Psoriasis is a chronic inflammatory skin disorder characterized by immune cell infiltration in the skin dermis, concomitant with hyperproliferation of epidermal keratinocytes, leading to a thickening of the epidermis and stratum corneum. The Interleukin-23 (IL-23)/IL-17/IL-22 cytokine axis, TNF- $\alpha$, and IL-1 $\beta$ are important inflammatory mediators in the pathogenesis of psoriasis $[1,2]$.

Integrins are a family of transmembrane receptors consisting of an alpha and a beta chain that interact with the extracellular matrix (ECM) to mediate cell behavior, including growth, differentiation, adhesion, and motility [3]. It has been reported that $\alpha 5 \beta 1$ integrin is overexpressed in the non-lesional psoriatic epidermis, compared with normal skin [4-6]. The overexpression of integrin $\alpha 5 \beta 1$ in keratinocytes of transgenic mice results not only in epidermal hyperproliferation, but also skin inflammation, providing a possible explanation for its pathogenic role [7]. In addition, integrin $\alpha 5 \beta 1$ is the primary receptor for fibronectin (Fn) $[5,8]$. Their interaction has been reported to induce proliferative signaling in endothelial cells and smooth muscle cells $[9,10]$. However, it is yet to be determined whether an $\alpha 5 \beta 1$ integrin antagonist is able to reduce the abnormal keratinocyte proliferation in psoriatic skin. 
The synthetic C16 peptide (KAFDITYVRLKF) represents a functional domain in the laminin111 $\gamma$ chain responsible for regulating angiogenesis [11,12]. Recently, C16 has been reported to have anti-inflammatory activity; systemic injection of $\mathrm{C} 16$ was shown to prevent leukocyte infiltration and alleviate detrimental inflammation in a rat model of acute allergic encephalomyelitis [13-15]. C16 is capable of binding to $\alpha 5 \beta 1$ integrin, shown by affinity chromatography, blocking the association of $\alpha 5 \beta 1$ integrin with Fn [12], but the influence of the $\mathrm{C} 16$ and $\alpha 5 \beta 1$ integrin association on keratinocytes, in response to $\mathrm{Fn}$, remains unclear.

Imiquimod (IMQ) is a toll-like receptor (TLR)7/8 agonist that has the ability to induce psoriasiform skin in humans and mice and to trigger a series of cytokines involved in the development of psoriasis, such as IL-23, IL-17, and IL-22 [2,16,17]. In this study, we investigated the effect of C16 on IMQ-induced psoriasis-like skin inflammation in mice. Our data show that $\mathrm{C} 16$ and a C16-derived short peptide (C16SP) could effectively alleviate the symptoms of psoriasis-like skin inflammation by inhibiting the hyperproliferation of keratinocytes, infiltration of neutrophils/macrophages, and generation of inflammatory cytokines. Our data indicate that the synthetic C16 and C16SP peptides are effective for the treatment of psoriasis in experimental animals.

\section{Results}

2.1. C16 Peptide Disrupts the Fibronectin-Induced Cytoskeletal, Proliferative, and Inflammatory Responses in HaCat Cells

HaCaT cells are immortalized human adult keratinocytes and are often used as a cellular model of psoriasis [18]. Moreover, expression of the integrins $\alpha 5$ and $\beta 1$ in HaCat cells suggests that these play a role in maintaining keratinocyte proliferation in culture [18-20]. Our immunofluorescence staining study also showed the $\alpha 5$ integrin expressed in HaCat cells (Figure 1a). We first determined the effect of C16 on Fn-mediated focal adhesion (FA) formation. Serum-starved subconfluent HaCat cells were cultured on glass coverslips precoated with Fn. Immunofluorescence staining of FA components, including focal adhesion kinase (FAK) and F-actin, showed that nearly $86 \%$ of cells were expressed marked FA and formed fine stress fibers (Figure 1b,c; C16 solvent as control). In contrast, following $\mathrm{C} 16$ and C16SP treatment for $3 \mathrm{~h}$, the FA-expressing cells were significantly reduced to levels of approximately $33 \%$ and $43 \%$, respectively. Control peptide (NITYVALKF) had no effect on the $\alpha 5 \beta 1$ integrin/Fn-induced cytoskeletal responses.

Next, the $\alpha 5 \beta 1$ integrin/Fn-induced cell proliferation was investigated. HaCat cells were cultured on a culture plate coated with Fn and incubated in low serum medium ( $2 \%$ FBS) containing $10 \mu \mathrm{M}$ C16 or C16SP for $24 \mathrm{~h}$. The numbers of cells were evaluated using a DNA-binding dye-based kit, showing that Fn-coating promoted HaCat cell proliferation compared to cells grown on an uncoated plate (Figure $1 \mathrm{~d} ; 124 \pm 4 \%$ versus $100 \pm 8 \%$ ). The C16 and C16SP treatment substantially suppressed Fn-induced cell proliferation to levels of approximately $97 \%$ and $99 \%$, respectively. Control peptide had no such effect.

Fn has been found in a soluble form in plasma and is abnormally expressed by dermal fibroblasts in the psoriatic non-lesional skin [5,6]. It has been reported that engagement of $\alpha 5 \beta 1$ integrin with Fn induces the NF-KB-dependent inflammatory program in endothelial cells [21]. We used TNF- $\alpha$ as an inflammatory marker to investigate whether C16 has the ability to suppress $\alpha 5 \beta 1$ integrin/Fn-mediated inflammation. HaCat cells were treated with both soluble Fn and $\mathrm{C} 16$ for $3 \mathrm{~h}$ and TNF- $\alpha$ gene expression was monitored by real-time qPCR. Soluble Fn induced TNF- $\alpha$ mRNA expression, approximately 21 -fold greater than the untreated control cells (Figure 1e). However, cells treated with Fn in the presence of C16 and C16SP for $3 \mathrm{~h}$ led to 7.1-fold and 7.5-fold lower levels of TNF- $\alpha$ mRNA expression than cells treated with $\mathrm{Fn} /$ solvent. Taken together, $\mathrm{C} 16$ and C16SP can serve as an $\alpha 5 \beta 1$ integrin antagonist to impair Fn-mediating signaling in HaCat cells. 
a

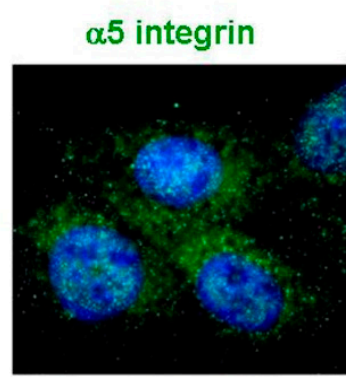

FITC $2^{\text {nd }} A b$ b
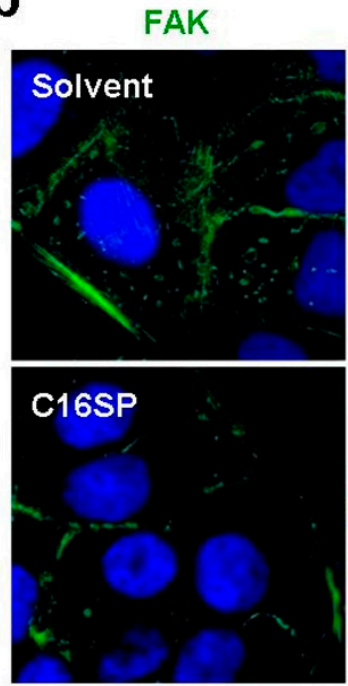

d

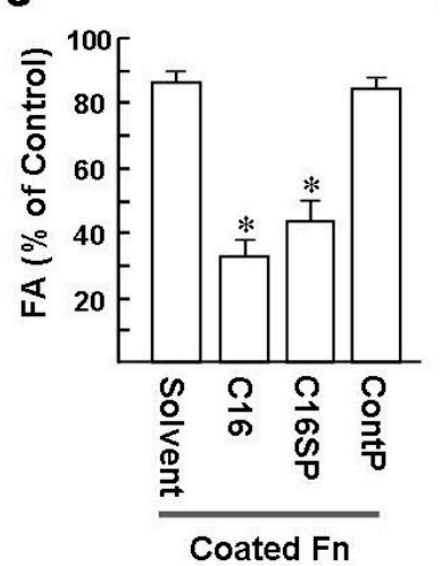

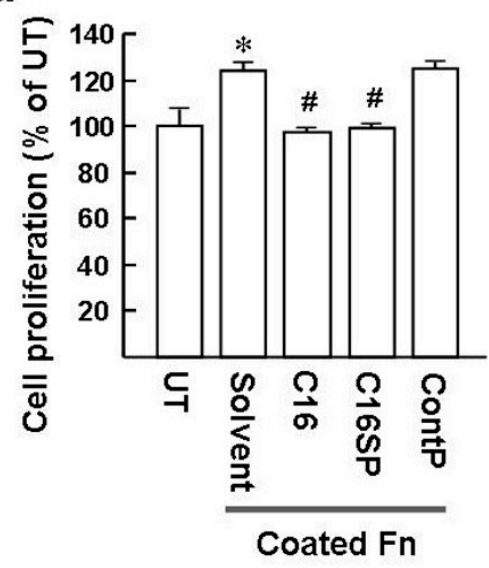

FAK F-actin
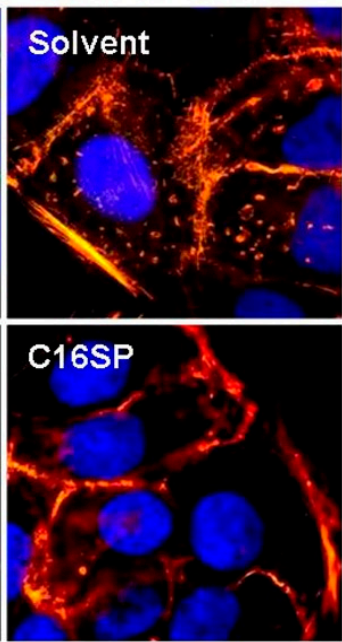

e

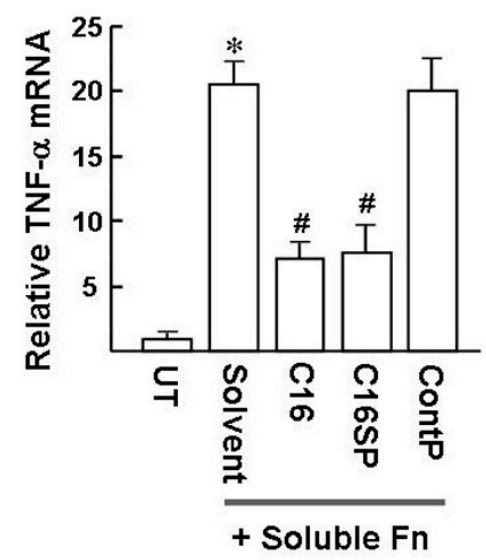

Figure 1. C16 peptide blocks $\alpha 5 \beta 1$ integrin-induced cellular responses in HaCat cells. (a) Immunofluorescence staining of $\alpha 5$ integrin. Representative images of three independent experiments. Nuclei were visualized with Hoechst 33258 stain. Original magnification, $\times 1000$. NC: Immunofluorescence staining with FITC-conjugated secondary antibody alone. (b) Immunofluorescence staining. Subconfluent HaCat cells were plated on Fn-coated coverslips and incubated in low-serum medium ( $2 \%$ FBS) for $16 \mathrm{~h}$ prior to treat with $10 \mu \mathrm{M} \mathrm{C16SP}$ or solvent for a further $3 \mathrm{~h}$. Representative images of three independent experiments show focal adhesion kinase (FAK) and stress fiber (TRITC-phalloidin staining). (c) The percentages of HaCat cells with marked FAK-positive focal adhesions (FA), per total cells, were calculated from 10 randomly selected microscopic fields in each treatment. Results are expressed as mean \pm SD of three independent experiments. ${ }^{*} p<0.0001$ versus solvent-treated cells. (d) Effect of the C16 on HaCat cell proliferation. Cell culture and treatment are described in the Methods. The proliferation index of each treatment was compared with the cells cultured on plates without Fn-coating (untreated; set as $100 \%$ ). ${ }^{*} p<0.03$ versus untreated (UT; Fn-uncoated and medium containing $2 \%$ FBS). ${ }^{\#} p<0.004$ versus solvent-treated cells. (e) $2 \times 10^{5}$ HaCat cells were incubated in serum-free medium for $16 \mathrm{~h}$, and then treated with Fn $(5 \mu \mathrm{g} / \mathrm{mL})$ and $10 \mu \mathrm{M}$ peptide in fresh serum-free medium for another $3 \mathrm{~h}$. Real-time qPCR analysis was conducted to determine the TNF- $\alpha$ mRNA levels. Gapdh was used as a loading control. Data are representative of three independent experiments. ${ }^{*} p<0.0003$ versus untreated cells. ${ }^{*} p<0.001$ versus solvent/Fn-treated cells. 


\subsection{Mitogenic Signaling Pathways Linking Integrin and Growth Factor Receptor in HaCat Cells are Blocked by $\mathrm{C} 16$}

Psoriatic epidermis formed by the hyperproliferation of keratinocytes is one of major sources of inflammatory mediators in skin lesions [1,22]. We investigated the molecular mechanism of integrin and growth factor receptor signaling on HaCat cell proliferation to understand more how $\mathrm{C} 16$ provides a novel strategy for psoriasis therapy. Fn induces FAK autophosphorylation on the Tyr397 residue (p-FAK) that has been shown to be crucial for $\alpha 5 \beta 1$ integrin-mediated signaling cascades involved in cell adhesion, migration, and proliferation [23]. In addition, Tyr397 phosphorylation is a key event for subsequent full activation of FAK [24,25]. As expected, serum-starved HaCat cells treated with Fn underwent transient p-FAK induction at $5 \mathrm{~min}$, assessed by western blot analysis (Figure 2a). As shown in Figure 1d, serum-starved HaCat cells, exposed to Fn in combination with 2\% FBS (Fn/FBS), showed significant proliferation. Further, 2\% FBS treatment increased the levels of p-FAK at 40 180 min compared to untreated cells ( $0 \mathrm{~min}$ ). In particular, we observed that stimulation of cells with Fn/FBS caused a synergistic induction of the Tyr397 phosphorylation by $\sim 2$-fold, compared to $2 \%$ FBS, over the time period examined. Phosphoinositide 3-kinase (PI3K)/protein kinase B (Akt) has been reported to be one of the main signaling molecules positioned downstream of FAK [26]. Western blot analysis revealed that phosphorylation of Akt on Thr308 (p-Akt) was slightly increased upon FN stimulation at 5 40 min. HaCat cells exposed to 2\% FBS had levels of p-Akt increased by 2-fold at all time points (5 180 min) compared to untreated cells. Moreover, Fn/FBS substantially induced the levels of p-Akt by $\sim 2$-fold compared to $2 \%$ FBS at time points from 10 to $180 \mathrm{~min}$. These results imply that the association of $\alpha 5 \beta 1$ integrin with Fn is linked with serum factors-mediated signaling to synergistically potentiate FAK/PI3K/Akt signaling in HaCat cells.

The involvement of FAK/PI3K/Akt signaling in HaCat cell proliferation was further evaluated using chemical inhibitors, including NVP-TAE226 and PF-573228 (FAK inhibitors) and LY294002 (a PI3K inhibitor). Inhibiting FAK or PI3K/Akt resulted in almost complete suppression of HaCat cell proliferation stimulated by Fn/FBS (Figure 2b). In addition, both NVP-TAE226 and PF-573228 dramatically abrogated the induction of p-FAK by Fn/FBS to the basal level (Figure 2c). FAK inhibitors also diminished the Akt phosphorylation induced by Fn/FBS. These results support the crucial role of FAK/PI3K/Akt signaling on Fn/FBS-mediated HaCat cell proliferation. Treatment with C16 or C16SP, but not control peptide, resulted in greatly decreased Fn/FBS-induced p-FAK and p-Akt, reaching a level similar to stimulation with 2\% FBS alone. Collectively, the inhibitory effects of C16 and C16SP on Fn/FBS-induced mitogenic signaling in HaCat cells may be due to attenuation of the interaction of $\alpha 5 \beta 1$ integrin with $\mathrm{Fn}$, leading to a blockade of integrin signaling, in synergy with serum-mediated signaling.

\subsection{Enhanced Expression of Fibronectin and $\alpha 5 \beta 1$ Integrin in IMQ-Treated Skin}

In the epidermis, basal keratinocytes use integrins to interact with the extracellular matrix (ECM) components at the dermal-epidermal junction (DEJ). It has been shown that integrin $\beta 1$ is a predominant epidermal integrin expressed in basal cells of the epidermis and dermal fibroblasts in murine skin, whereas integrin $\alpha 5$ is weakly expressed [27]. In addition, it is well established that integrin $\beta 1$ is critical for keratinocyte proliferation and skin integrity $[27,28]$. To determine the expression patterns of $\alpha 5 \beta 1$ integrin and Fn in murine psoriasis-like skin, the skin on the backs of mice was stimulated with IMQ for six consecutive days and their expression patterns were evaluated by immunofluorescence staining. As predicted, expression of integrin $\alpha 5$ and $\beta 1$ was observed in normal epidermis, but a discontinuous staining often appeared in the epidermal basal layer adjacent to the DEJ (Figure 3a). Keratinocyte hyperproliferation was observed in the epidermis in IMQ-treated skin and integrin $\alpha 5$ and $\beta 1$ were detected throughout the epidermal layers. The most notable feature was that the staining of integrin $\alpha 5$ was clearly stronger in the epidermal basal cell layer of IMQ-treated skin than in normal skin. In addition, we noted the accumulation of cell populations with high expression of $\alpha 5 \beta 1$ integrin in the dermis after IMQ stimulation. 
a
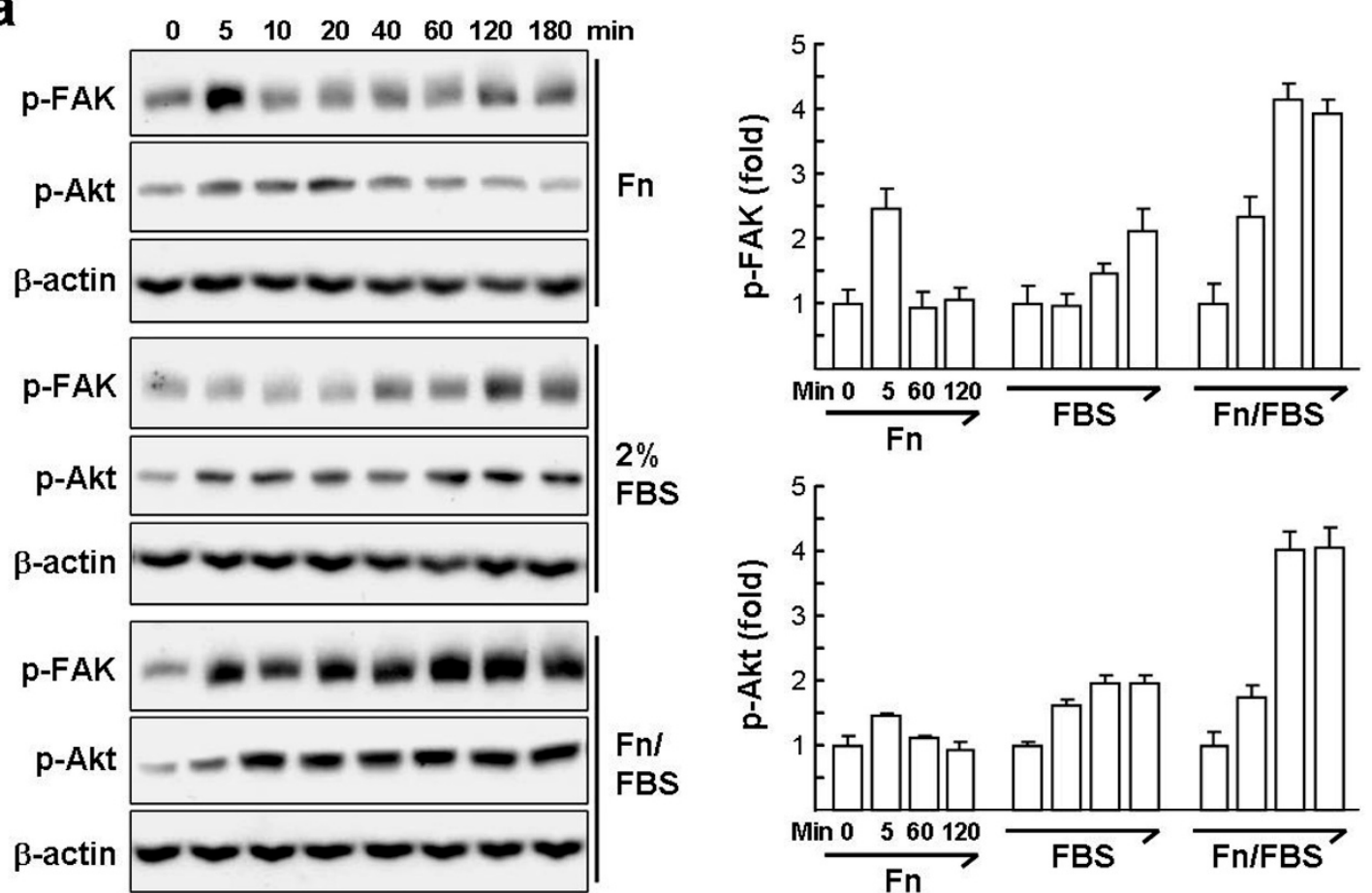

FBS

b

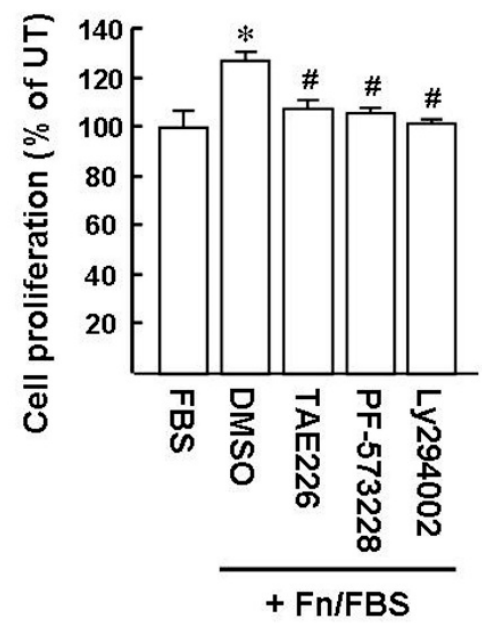

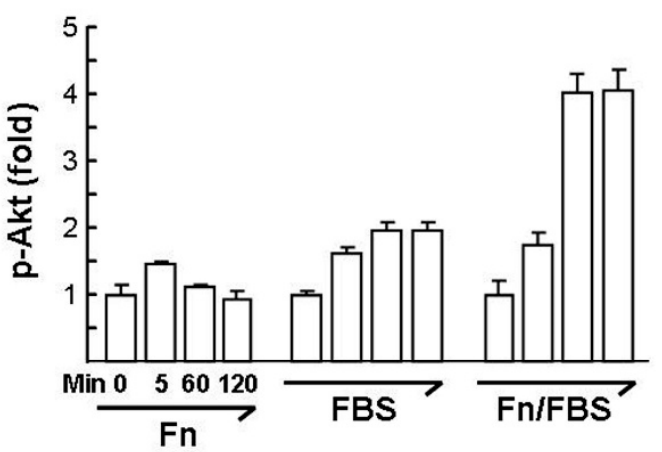

C

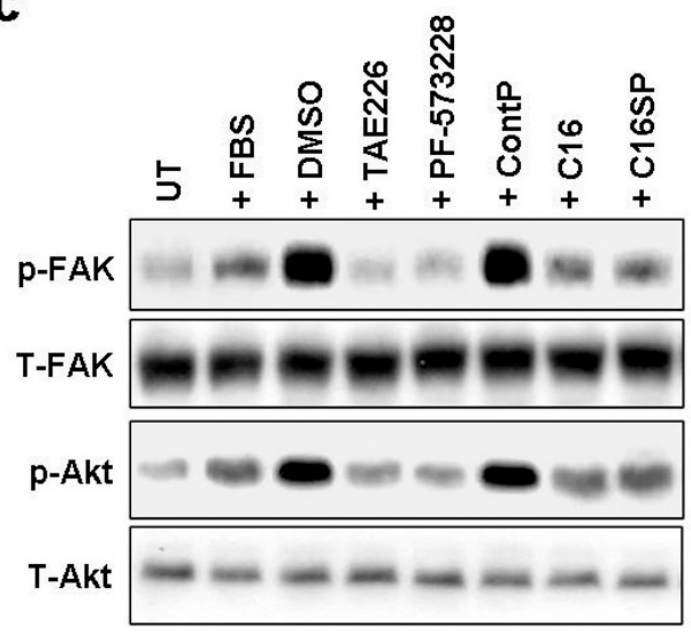

Figure 2. C16 and C16SP suppress Fn and serum-induced HaCat cell proliferation by blocking the FAK/PI3K/Akt signaling. (a) Fn and FBS synergistically induce phosphorylation of FAK at Y397 and Akt at T308 in HaCat cells in a time-dependent fashion. Cells were serum starved for $24 \mathrm{~h}$ and then treated with fresh medium containing $5 \mu \mathrm{g} / \mathrm{mL}$ of Fn or $2 \%$ FBS or both (Fn/FBS), for the time periods indicated. Representative immunoblots and densitometric analysis are from three independent experiments. $\beta$-actin served as a protein loading control. (b) Effect of the FAK inhibitors (NVP-TAE226 and PF-573228) and PI3K inhibitor (LY294002) on HaCat cell proliferation. Cells were serum starved for $24 \mathrm{~h}$ and then exposed to fresh medium containing $5 \mu \mathrm{M}$ FAK or PI3K inhibitor for 30 min before addition of Fn/FBS for another $24 \mathrm{~h}$. Cells treated with $2 \%$ FBS alone served as proliferative index $100 \%$. Data represent three independent experiments, each performed in quadruplicate. ${ }^{*} p<0.005$ versus FBS-treated cells. ${ }^{\#} p<0.002$ versus DMSO solvent-treated cells. (c) C16 and C16SP suppress Fn/FBS-induced phosphorylation of FAK and Akt. Serum-starved HaCat cells were treated with FAK inhibitor for $30 \mathrm{~min}$ or $10 \mu \mathrm{M} \mathrm{C} 16$ peptide for $60 \mathrm{~min}$ before Fn/FBS stimulation for $1 \mathrm{~h}$. One representative immunoblot from three independent experiments is shown. 


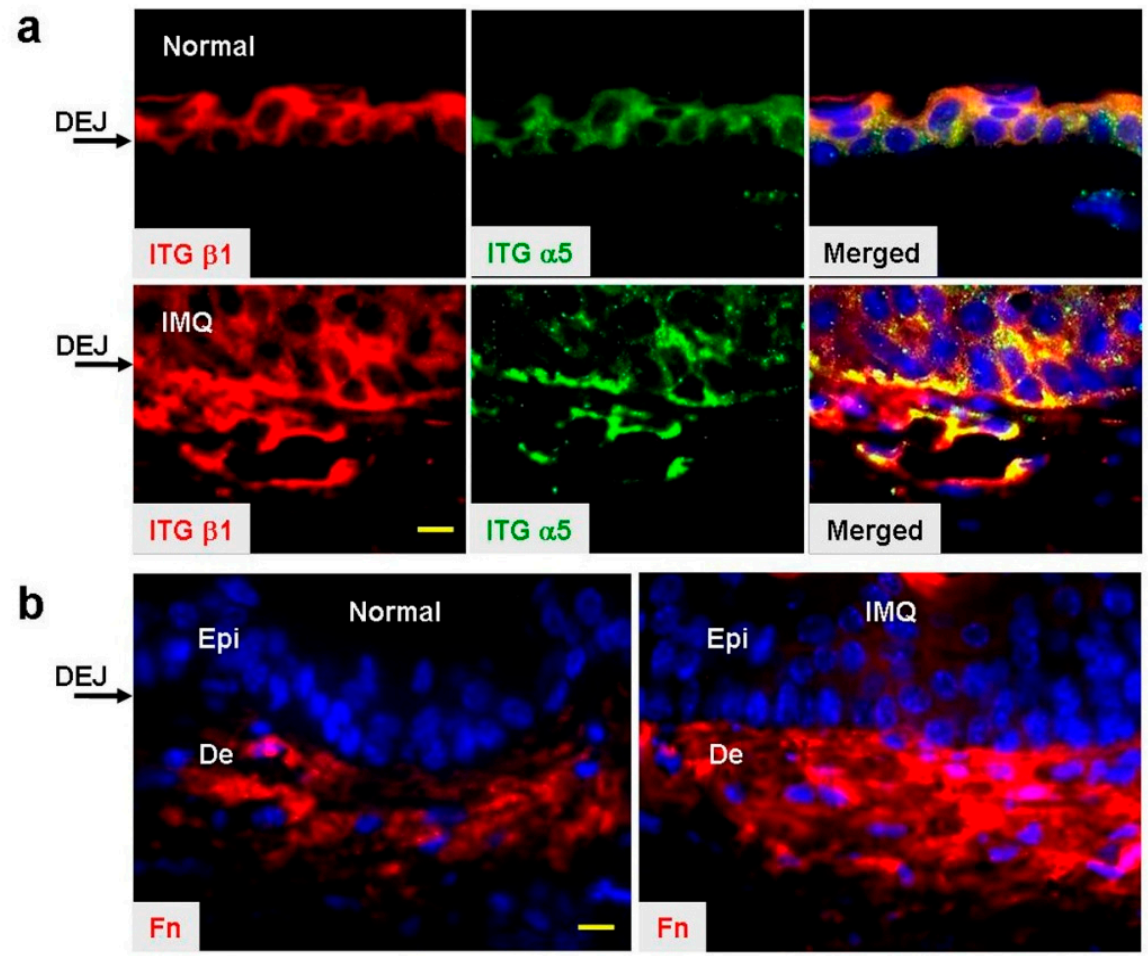

Figure 3. Immunofluorescence analysis of mouse dorsal skin six days after Imiquimod (IMQ) treatment. (a) Representative skin sections from mice treated with control cream (normal) or IMQ cream, and dual-immunofluorescence stained for integrin (ITG) $\alpha 5$ and $\beta 1$. Nuclei were stained by Hoechst 33258 (blue). DEJ: Dermal-epidermal junction. (b) Representative images of fibronectin (Fn) staining of normal and IMQ-treated skins. Epi: Epidermis; De: Dermis. Scale bar: $10 \mu \mathrm{m}$. Results were evaluated from six sections of a skin specimen, with three mice in each group.

Fn has been shown to be present in the upper dermis of normal murine skin, as judged by immunofluorescence [27]. As shown in Figure 3b, highly dense Fn staining in the dermis was a prominent feature in IMQ-treated skin, compared to normal skin. In addition, it was already known from in vitro studies that $\alpha 5 \beta 1$ integrin is responsible for polymerization of Fn [29]. Our immunofluorescence staining supporting the in vitro functional interaction between $\alpha 5 \beta 1$ integrin and Fn showed that an assembled Fn was aligned towards the integrin $\alpha 5 \beta 1$-enriched epidermal layer at the DEJ (Figure 3a,b; IMQ-treated skin). Taken together, our results indicate that IMQ stimulates the abnormal expression of $\alpha 5 \beta 1$ integrin and $F n$ in murine skin. The results imply that $\alpha 5 \beta 1$ integrin may interact with Fn at the DEJ after IMQ stimulation.

\subsection{C16 and C16SP Reduce the Symptoms of Imiquimod (IMQ)-Induced Psoriasis}

C16, C16SP, and DMSO vehicle were mixed with the IMQ cream to investigate their therapeutic effects on psoriasis. Subsequently, the mixed IMQ cream was applied topically to the shaved back skin and right ears of BALB/c mice, once per day for six consecutive days. On day 7, the dorsal skin of mice treated with IMQ/vehicle displayed apparent erythema and desquamation (Figure 4a). However, mice treated with C16SP showed a significant reduction of the erythema and desquamation in the back skin. Ear swelling is an inflammatory marker in this mouse model. IMQ/vehicle treatment increased the ear thickness by 1.9-fold, compared to the untreated control (Figure $4 \mathrm{~b}$ ). Treatment with C16 and C16SP reduced the ear thickening compared to IMQ/vehicle group (432 \pm 21 and $437 \pm 22$ versus $592 \pm 18 \mu \mathrm{m}$ ). However, control peptide did not suppress the IMQ-induced skin inflammation. Histological analysis of back skin by hematoxylin and eosin (H\&E) staining also showed that the $\mathrm{IMQ} /$ vehicle group exhibited several important features of psoriasiform histology, including acanthosis (thickening of the epidermis), hyperkeratosis (thickening of the stratum corneum), and parakeratosis 
(retention of nuclei in the stratum corneum) (Figure 4c). In contrast, C16SP treatment resulted in a smoother epidermis than the IMQ/vehicle treatment, indicating the pathological phenotype was improved. Statistically, IMQ/vehicle significantly stimulated the epidermal thickening compared to normal skin $(122 \pm 10.5$ versus $12.0 \pm 0.8 \mu \mathrm{m})$, whereas C16 and C16SP led to a reduction in epidermal thickness ( $35.3 \pm 4.1$ and $39.2 \pm 2.7 \mu \mathrm{m}$, respectively).

a

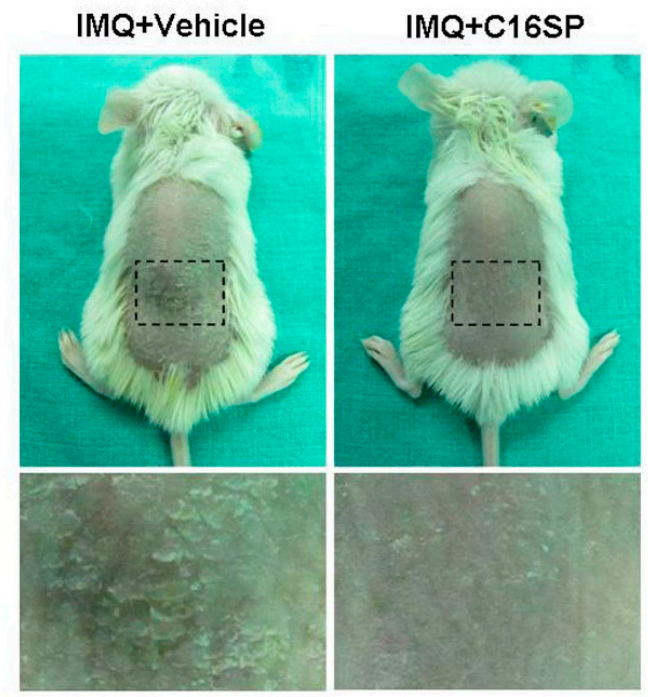

b

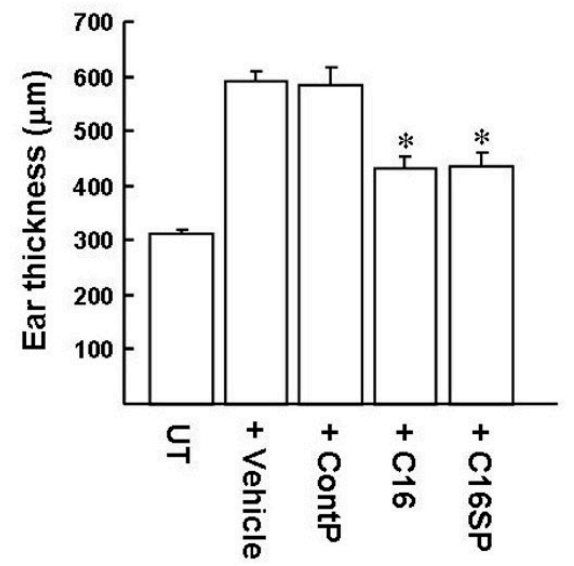

C
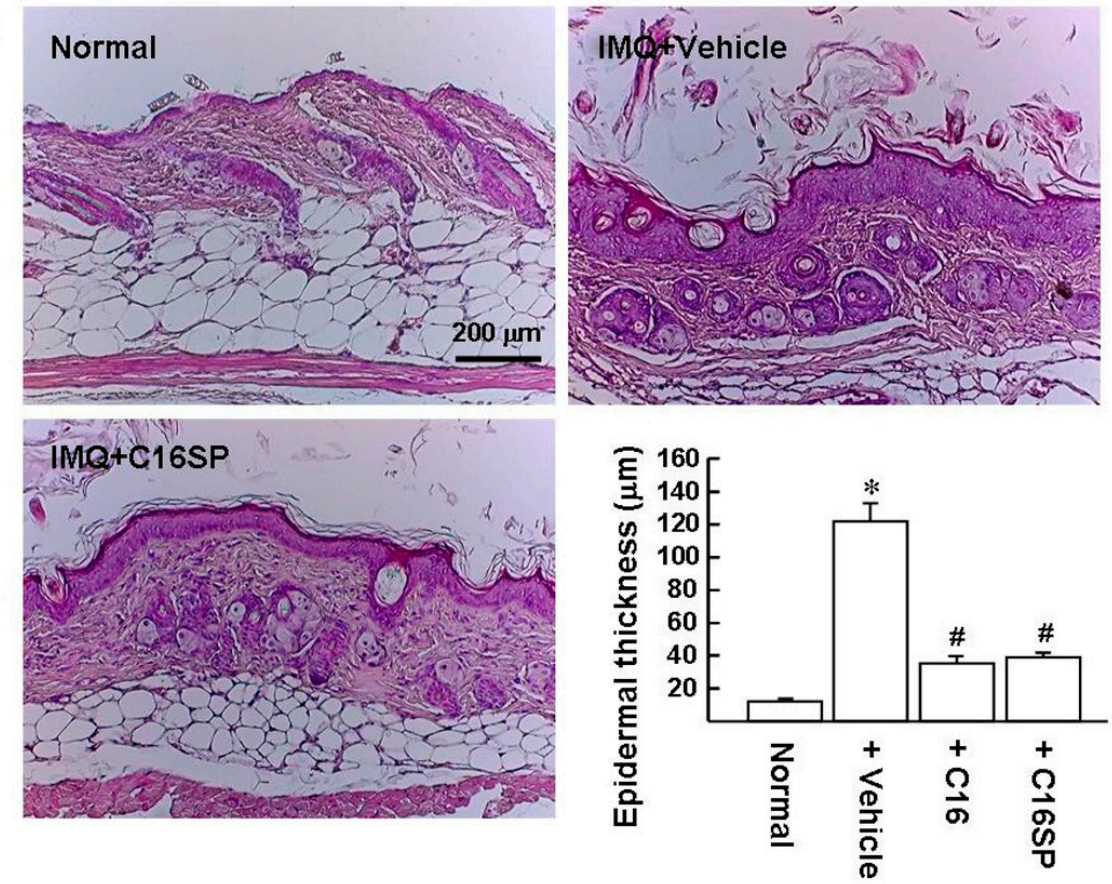

Figure 4. C16 and C16SP improve the symptoms of IMQ-induced psoriasis. BALB/c mice (eight-week-old) received a daily topical treatment with IMQ cream on the shaved back and right ear for six consecutive days. (a) Physical appearance of the back skin at the end of the study. Insert: Back skins photographed at higher magnification with a light-field camera. (b) Ear thickness measured by digital micrometer. ${ }^{*} p<0.001$ versus IMQ/vehicle-treated group. (c) Histopathological examination of H\&E stained dorsal skin. Representative images from three independent experiments with six mice per group are shown. The measurement of epidermal thickness is described in the Methods. Results are expressed as mean $\pm \mathrm{SD} .{ }^{*} p<0.0001$ versus normal control group. ${ }^{\#} p<0.0005$ versus IMQ/vehicle treatment. 
Hyperproliferation of keratinocytes is one of the main manifestations of psoriatic lesions. We monitored the IMQ-induced keratinocyte proliferation by BrdU labeling to investigate the acanthosis suppressed by the C16. Mice back skins were treated with IMQ for five days and then intraperitoneally injected with BrdU for another $24 \mathrm{~h}$. Immunohistochemical analysis of the IMQ/vehicle group showed that the BrdU-positive cells were mostly distributed in the basal layer of the epidermis with dysregulated proliferation, in comparison with IMQ/C16SP (Figure 5a). Statistically, the numbers of IMQ-induced BrdU-positive basal cells were significantly reduced in mice treated with C16 and C16SP, compared with vehicle treatment ( $200 \times$ field: $8.5 \pm 1.4$ and $8.3 \pm 1.4$ versus $24.5 \pm 2.0$; Figure $5 b$ ). Collectively, these data suggest that $\mathrm{C} 16$ and $\mathrm{C} 16 \mathrm{SP}$ are capable of improving the symptoms of psoriasis.

a
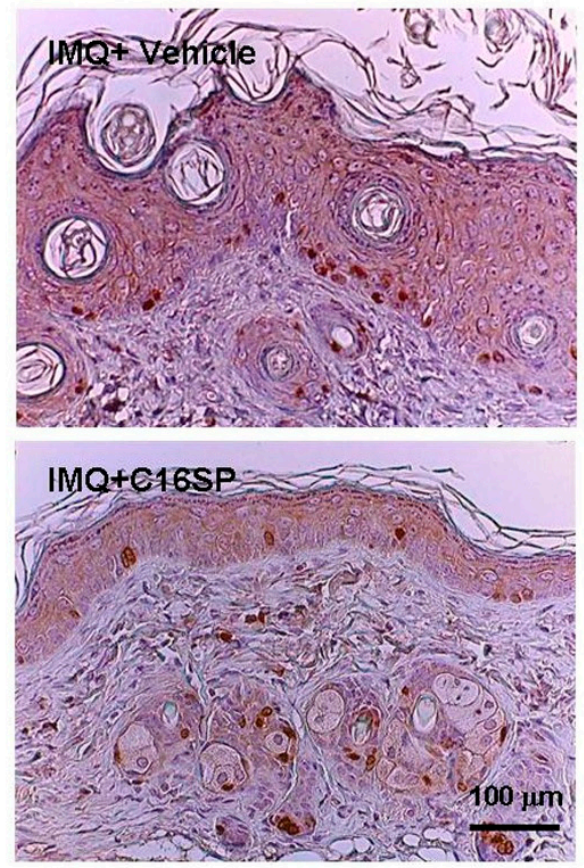

b

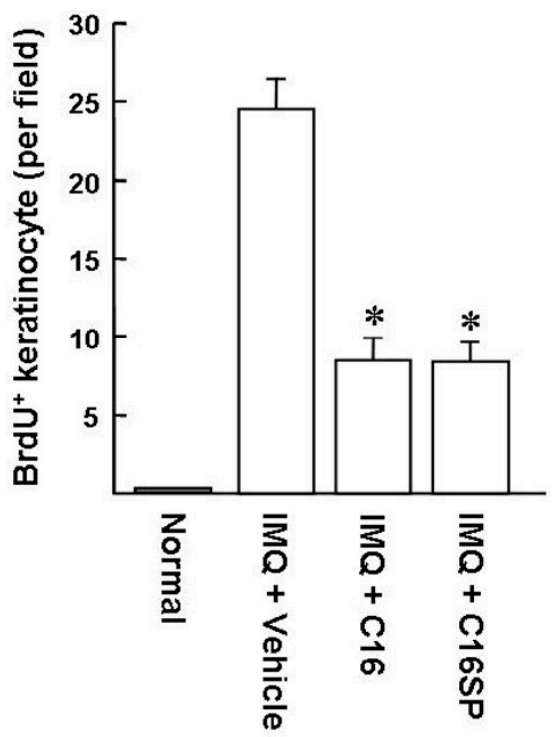

Figure 5. C16 and C16SP suppress IMQ-induced keratinocyte proliferation. Murine dorsal skins were treated with IMQ for five consecutive days and then intraperitoneally injected with BrdU for another $24 \mathrm{~h}$, before being euthanized. (a) BrdU immunostaining (brown) and counterstaining with hematoxylin. Representative images are from six sections per mouse skin, with six mice per group. (b) Numbers of BrdU-positive cells in the basal layer of the epidermis. The digital image analysis of $\mathrm{BrdU}^{+}$keratinocytes was performed blinded on an average of six randomly selected 200× magnification fields from each section, using a Nikon Eclipse 80i microscope equipped with a Leica DC 500 camera. * $p<0.0001$ versus IMQ/vehicle-treated group.

\subsection{C16 and C16SP Suppress IMQ-Induced Inflammatory Responses in the Skin}

The development of IMQ-induced psoriasis is dependent on several inflammatory cytokines. After IMQ/vehicle stimulation for four consecutive days, the levels of inflammatory cytokines were evaluated by real-time qPCR. The expression levels of the TNF- $\alpha, I L-1 \beta, I L-23, I L-17 A$, IL-22, and IL-6 genes were significantly increased in the skin stimulated by IMQ/vehicle, compared with the untreated control group (Figure 6; IMQ/vehicle set as 100\%). Notably, these cytokine gene expression levels were markedly reduced in the IMQ/C16SP group, by a factor of 3 5-fold. 

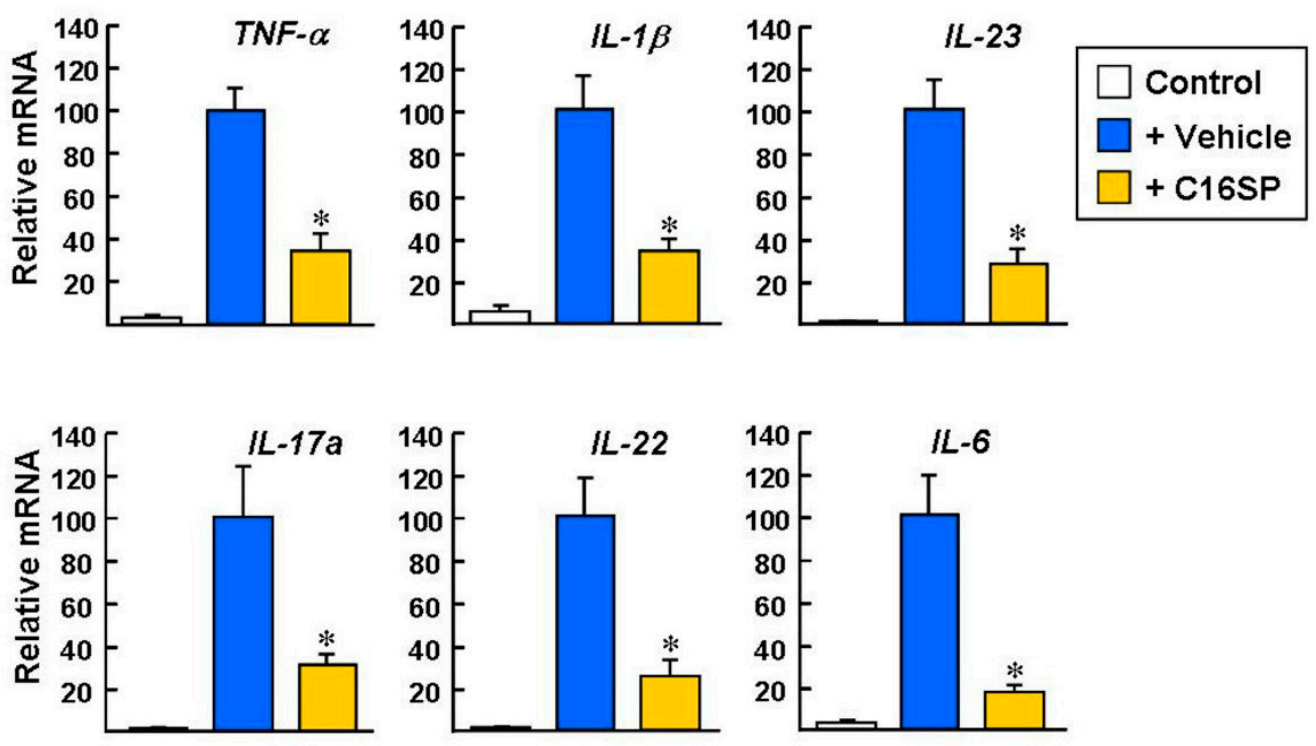

Figure 6. Real-time qPCR analysis of the expression levels of inflammatory cytokines induced by IMQ. Mice dorsal skins were treated with IMQ plus vehicle, C16, or C16SP for four consecutive days and then the dorsal skin samples were analyzed. Control indicates mice that received cream without IMQ. Gapdh was used as a loading control. Data are from three independent experiments. ${ }^{*} p<0.0001$ versus $\mathrm{IMQ} /$ vehicle-treated group.

Infiltration of neutrophils and macrophages in psoriatic skin plays an important role in the promotion and persistence of chronic skin inflammation $[2,17,30]$. Here, we investigated whether C16 and C16SP could ameliorate the infiltration of neutrophils and macrophages induced by IMQ stimulation. Immunofluorescence staining of the lymphocyte antigen 6 complex locus G (Ly6g; a neutrophil marker) revealed that the numbers of $\mathrm{Ly}_{6 \mathrm{~g}}{ }^{+}$cells were greatly increased in the dermal layer of the skin after IMQ/vehicle stimulation for six consecutive days (Figure 7a). However, treatment with $\mathrm{C} 16$ or C16SP suppressed the neutrophil accumulation, compared to IMQ/vehicle treatment $\left(\mathrm{Ly}_{6} \mathrm{~g}^{+}\right.$cells per $1000 \times$ field: $7.7 \pm 1.6$ and $7.9 \pm 1.2$ versus $18.6 \pm 2.2$; Figure $7 \mathrm{~b}$ ). In addition, immunofluorescent staining of the F4/80 (a macrophage marker) showed that C16 and C16SP effectively suppressed the macrophage infiltration, compared to IMQ/vehicle treatment $\left(\mathrm{F} 4 / 80^{+}\right.$cells per $1000 \times$ field: $8.0 \pm 2.2$ and $9.7 \pm 1.7$ versus $25.7 \pm 3.8$ ).

Neutrophil chemoattractants CXCL1/CXCL2 (CXC chemokine ligands 1/2) are expressed abundantly in lesional psoriatic skin and are produced by keratinocytes upon stimulation by Thelper type 17 (Th17) cytokines (such as IL-17 and IL-22) and TNF, contributing to pathogenic recruitment of neutrophils [2,31]. Th17 cytokines also induce psoriatic skin expressing macrophage chemokines, including CCL3 and CCL4 [2,32]. Furthermore, macrophages activated by inflammatory triggers also produce CXCL1 and CXCL2 [33]. To directly link the reduced infiltration of neutrophils and macrophages observed in the mice treated with both IMQ and C16, we investigated the expression of these chemokine genes by real-time qPCR assay. CXCL1/2 and CCL3/4 mRNA levels were significantly increased in the skin stimulated by IMQ, compared with the cream vehicle control group (Figure $7 \mathrm{c}$ ). In contrast, expression of these chemokine genes was significantly reduced in the IMQ/C16SP group, by a factor of $\sim 2.5$-fold. Taken together, our results indicate that C16 and C16SP can ameliorate IMQ-induced skin inflammatory responses in mice, including infiltration of neutrophils and macrophages, as well as expression of a series of inflammatory genes. 
a

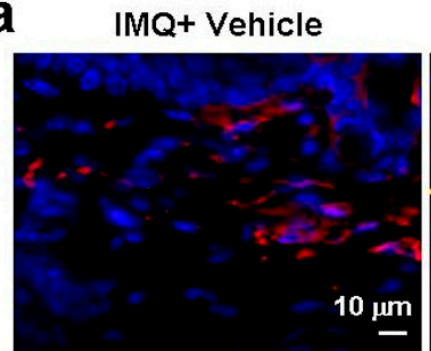

Ly $6 g^{+}$Neutrophils

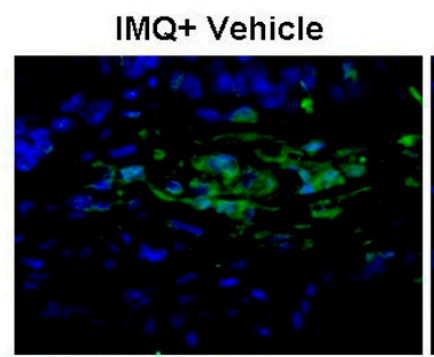

F4/80+ Macrophages b
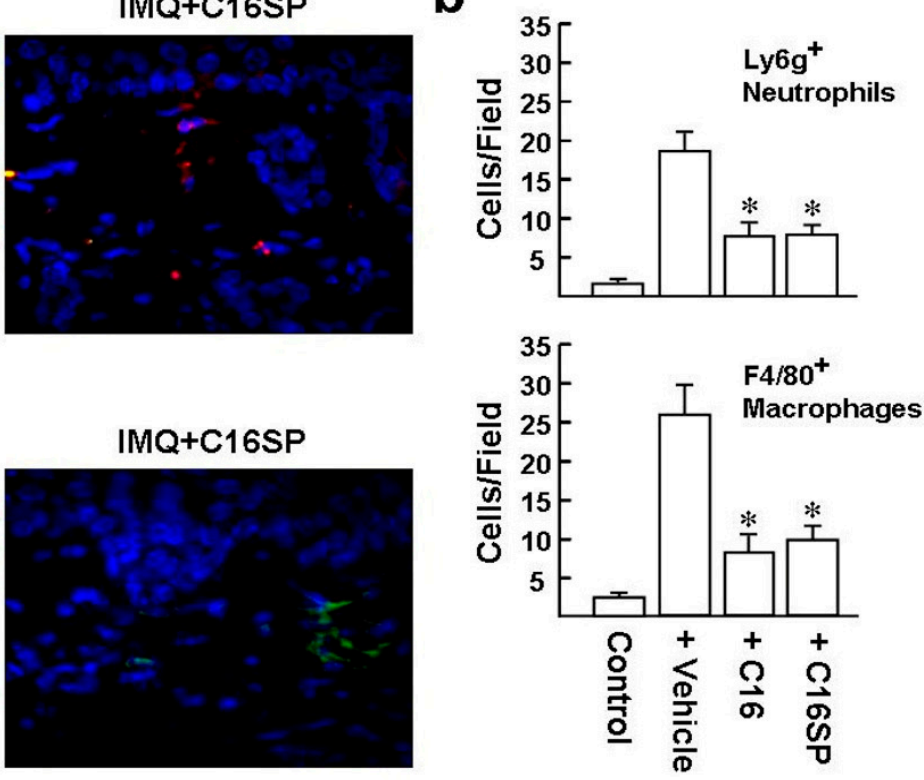

C
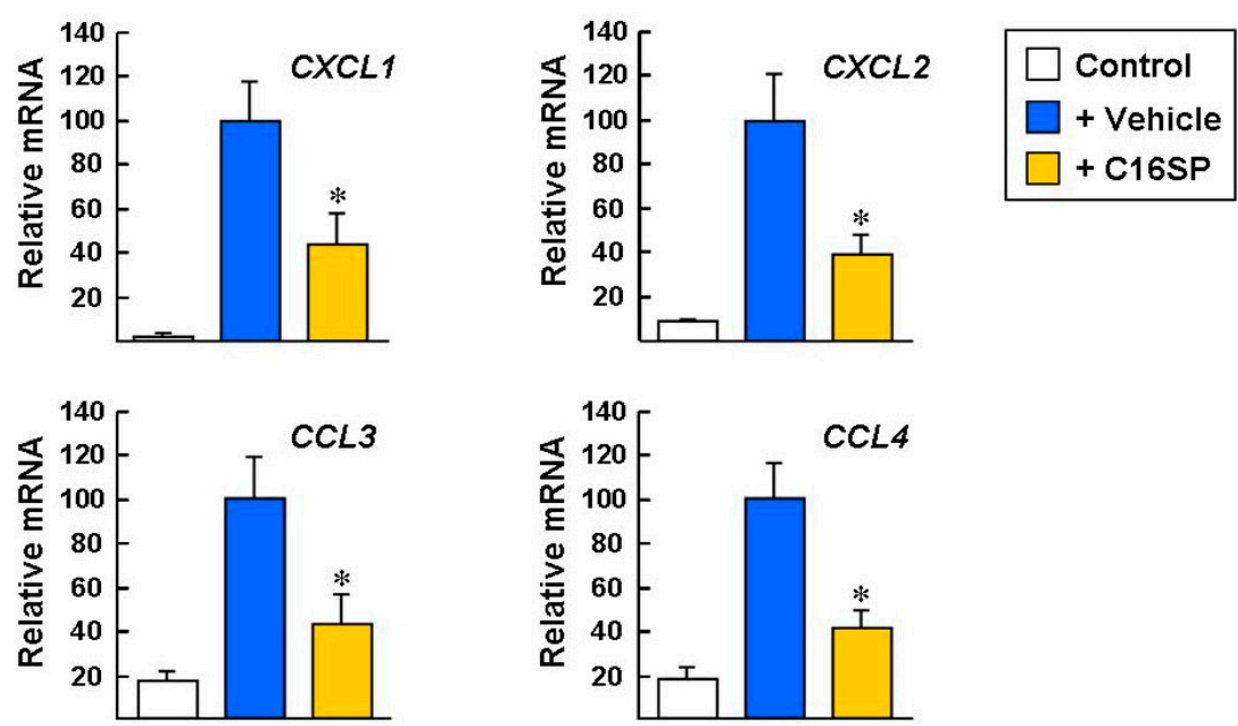

Figure 7. C16 and C16SP suppress IMQ-induced neutrophil and macrophage infiltration. (a,b) Mice dorsal skins were treated with IMQ cream plus vehicle, C16, or C16SP for six consecutive days. Immunofluorescence analysis of the levels of $\mathrm{Ly} \mathrm{g}^{+}$neutrophils (red) and $\mathrm{F} 4 / 80^{+}$macrophages ( $\mathrm{green}$ ). Nuclei were visualized with Hoechst 33258 staining. Representative images are from six sections per mouse skin, with six mice per group. The digital image analyses of $\mathrm{Ly}^{6} \mathrm{~g}^{+}$and $\mathrm{F} 4 / 80^{+}$cells were performed blinded on an average of 6 randomly selected 1000× magnification fields from each section, using a Zeiss epifluorescence microscope and Zeiss software. Control indicates mice which received cream without IMQ. * $p<0.002$ versus IMQ/vehicle-treated group. (c) Murine dorsal skins were treated with IMQ cream plus vehicle or C16SP for four consecutive days. Real-time qPCR analysis of the levels of chemokines. Gapdh was used as a loading control. Data are from three independent experiments. * $p<0.05$ versus IMQ/vehicle-treated group.

\section{Discussion}

Integrin $\alpha 5 \beta 1$ expression has been reported to be maintained at a steady state in normal human adult epidermis $[5,34]$. Previous studies have shown that increased expression of $\alpha 5 \beta 1$ integrin 
in the epidermis and Fn enrichment at the DEJ are features of the non-lesional skin of psoriasis patients [4-6,18,34]. The role of $\alpha 5 \beta 1$ integrin on the pathogenesis of psoriasis has been highlighted in transgenic mice that overexpress $\alpha 5 \beta 1$ integrin in keratinocytes, with dramatic effects including epidermal hyperproliferation and inflammation [7]. We observed that the interaction of $\alpha 5 \beta 1$ integrin with Fn induced TNF- $\alpha$ expression in HaCat cells. This provides a molecular mechanism to support the pathogenic role of $\alpha 5 \beta 1$ integrin and Fn in skin inflammation. Furthermore, anti-TNF therapy by biological agents constitutes a first-line treatment of moderate-to-severe psoriasis [35]. In this study, C16 and C16SP showed marked efficacy in suppressing TNF- $\alpha$ gene expression in vitro and in vivo, showing an alternative pathway to control the TNF- $\alpha$ level in psoriatic skin. In the murine IMQ-induced, psoriasis-like skin inflammation model, we found that the amounts of $\alpha 5 \beta 1$ integrin and Fn proteins were dramatically increased at the DEJ, strikingly similar to their expression in human non-lesional psoriatic epidermis and psoriatic plaques. Therefore, this animal model may be appropriate for evaluating drug candidates targeting the $\alpha 5 \beta 1$ integrin. To the best of our knowledge, the current study is the first to show that an integrin antagonist has therapeutic potential for psoriasis.

It is well known that growth factors-associated matrigel or the ECM has the ability to regulate cell proliferation, in contrast with growth factors-reduced ECM [36]. In addition, growth factor-free Fn-coated slides are unable to induce HaCat cell proliferation [36]. Therefore, cellular behavior, such as proliferation, is regulated by the crosstalk between integrin signals and growth factor signals. FAK plays a critical role in the convergence of growth factor and integrin signaling pathways. For example, synergism in induction of autophosphorylation of FAK on Y397 has been observed in cells stimulated with Fn and angiotensin II [37], as well as Fn and platelet-derived growth factor (PDGF) [26,38]. Clustering of integrin by Fn induces FAK autophosphorylation and results in activation of several downstream pathways, including PI3K/Akt [26,39,40]. Also, Akt is a downstream target of growth factor receptors and can directly phosphorylate FAK at Ser695 and Thr700 that is essential for the recruitment of Src kinase to form the FAK-Src complex [39,41]. The FAK-Src complex facilitates FAK autophosphorylation induced by growth factors, subsequently, in synergy with integrin-mediated FAK signaling to control cell behavior [39,41,42]. Our result reveals that FAK autophosphorylation follows Akt phosphorylation induced by $2 \%$ FBS in HaCat cells, supporting the novel effect of Akt on FAK autophosphorylation. These molecular mechanisms may provide a possible explanation for our observation that $2 \%$ FBS synergizes functionally with Fn/integrin signaling in mediating HaCat cell proliferation. A previous study showed that $\mathrm{C} 16$ can bind to $\alpha 5 \beta 1$ integrin to block its association with Fn [12]. Our in vitro study supports the C16 effect with evidence that the connection of $\mathrm{Fn} / \alpha 5 \beta 1$ integrin signaling and growth factor signaling on FAK/Akt is blocked by C16. The IMQ-induced psoriasis-like skin condition in mice is mediated by several crucial cytokines, of which IL-17A and IL-22 are known to activate PI3K/Akt signaling in epidermal keratinocytes to induce abnormal cell proliferation $[43,44]$. C16 effectively prevents IMQ-induced keratinocyte hyperproliferation in vivo. This result leads us to assume that the IL-23/IL-17/IL-22 axis connects with Fn/ $\alpha 5 \beta 1$ integrin as a pathogenic mechanism in the development of psoriasis.

Here, we report that C16 and C16SP have beneficial pharmacological properties, such as blockage of neutrophil infiltration in psoriatic skin. Polymorphonuclear neutrophils (PMNs) are the most abundant circulating leukocytes of the innate immune system and PMN infiltration into the epidermis is a hallmark of psoriasis [1]. PMNs express several surface integrins, including $\alpha 5 \beta 1$, that are involved in their inflammatory infiltration [45]. However, whether C16 can interfere directly with PMN migration into the ECM awaits further investigation. In addition, interaction of $\alpha 5 \beta 1$ integrin with Fn has been shown to promote cell survival by activation of FAK-mediated signals [46]. This may be involved in the delayed apoptosis of PMNs during chronic inflammation [47]. The ability of C16 to block $\alpha 5 \beta 1$ integrin-mediated survival signaling in PMNs has yet to be investigated.

Integrin $\alpha v \beta 3$ is a receptor for vitronectin and, reportedly, is not expressed in normal human keratinocytes [48]. Integrin $\alpha \mathrm{v} \beta 3$ is a predominant integrin expressed in inflammatory macrophages and participates in activation of the NF-KB-mediated inflammatory signaling [49]. Notably, inflammatory 
macrophages play an important role in the progression of psoriasis; they release IL-23 to drive and maintain the differentiation of Th17 [50]. C16 has been reported to be an $\alpha \mathrm{v} \beta 3$ integrin antagonist and to improve neuroinflammatory disease in experimental animals [13-15]. In our study, it still remains uncertain whether $\mathrm{C} 16$ acts against $\alpha \mathrm{v} \beta 3$ integrin to define the macrophage infiltration in skin stimulated by IMQ.

Traditional systemic therapies (glucocorticosteroids, methotrexate, cyclosporine, and retinoids) for psoriasis are often not able to meet the desired treatment goals, and high-dose and/or long-term use may be associated with toxicity, resulting in organ damage, such as nephrotoxicity, hypertension, bone marrow toxicity, and hepatotoxicity [51,52]. Several classes of biologicals have been developed against inflammatory cytokines, including TNF- $\alpha$, IL-22, IL-23, and IL-17, although they are not effective in all individuals with psoriasis [51,53]. In addition, these biologicals cause some side effects, particularly the development of infectious diseases and increases in cancer risks [51-54]. Currently, patient satisfaction regarding psoriasis therapy remains low, and new drugs with better efficacy, a lower price, and fewer adverse effects are needed. Anti-integrin-based therapy provides an alternative strategy to resolve inflammatory diseases, such as Lifitegrast, a new FDA-approved therapy for dry eye disease. Lifitegrast is designed to mimic the intracellular adhesion molecule-1 (ICAM-1) for blocking the leukocyte function-associated antigen-1 (LFA1 or integrin $\alpha \mathrm{L} \beta 2$ ), resulting in reducing the $\mathrm{T}$ cells homing to the ocular surface [55]. The systemic administration of $\mathrm{C} 16$ has been shown to treat acute experimental allergic encephalomyelitis in rats and to have high degrees of safety and efficacy [13-15]. These reports imply that C16 may have a potential application for psoriasis therapy via systemic administration.

\section{Materials and Methods}

\subsection{Materials}

The peptides were synthesized, modified for stability by acetylation at the $\mathrm{NH}_{2}$ termini and amidation at the $\mathrm{COOH}$ termini, and characterized by mass spectrometry ( $>90 \%$ purity) at GenScript (Piscataway, NJ, USA). Dulbecco's modified Eagle's medium (DMEM), fetal bovine serum (FBS), antibiotic-antimicotic solutions, and trypsin were purchased from Invitrogen (Carlsbad, CA, USA). Fibronectin (F0895), 5-bromo-2'-deoxyuridine (BrdU), TRITC-phalloidin, Hoechst 33258 dye and all chemicals were from Sigma-Aldrich (St. Louis, MO, USA). Antibodies for BrdU (GTX42641) and fibronectin (GTX34727) were from GeneTex (Taipei, Taiwan). Phospho-FAK (Tyr397) antibody (\#3283), anti-FAK antibody (\#13009), phospho-Akt (Thr308) antibody (\#13038), and anti-Akt (pan) antibody (\#4691) were purchased from Cell Signaling Technology (Danvers, MA). Antibodies for integrin alpha 5 antibody (ab25251), integrin beta 1 (ab179471), Ly6g (PE/Cy7, ab25514), and F4/80 (ab6640) were from Abcam (Cambridge, MA, USA). FITC-donkey anti-rabbit IgG and FITC-donkey anti-mouse IgG were purchased from BioLegend (San Diego, CA, USA). NVP-TAE226, PF-573228, and LY-294002 were purchased from Selleckchem (Houston, TX, USA).

\subsection{Cell Culture}

The human keratinocyte cell line HaCaT was maintained in DMEM, supplemented with $10 \%$ $(v / v)$ FBS and antibiotic-antimicotic solutions at $37^{\circ} \mathrm{C}$ in a humidified $5 \% \mathrm{CO}_{2}$ atmosphere. HaCat cells were also cultured on glass coverslips precoated with the $\mathrm{Fn}(10 \mu \mathrm{g} / \mathrm{mL})$, according to the manufacturer's protocol.

\subsection{Cell Proliferation Assay}

HaCat cells $\left(1 \times 10^{3} /\right.$ well) were seeded in 96 -well cell culture plates (Costar; cat. no. 3599$)$ precoated with the Fn $(10 \mu \mathrm{g} / \mathrm{mL} ; 50 \mu \mathrm{L}$ per well $)$ and incubated in 10\% FBS culture medium for one day. HaCat cells cultured in uncoated wells served as a control. Subsequently, cells were maintained in serum-free DMEM for $3 \mathrm{~h}$ and then switched to stimulation medium, consisting of DMEM supplemented with $2 \%$ 
FBS and $10 \mu \mathrm{M}$ peptide, for a further $24 \mathrm{~h}$. Cell proliferation was evaluated by the Cell Proliferation Assay Kit (BioVision; Catalog \# K307-1000, Milpitas, CA, USA), following the instruction manual. All assays were performed in triplicate, and the experiment was repeated 4 times.

\subsection{Western Blot Analysis}

Cell lysis, SDS-PAGE, and antibodies use for immunoblotting were as described in a previous study [56]. The band intensity in immunoblots was evaluated with a Model GS-700 imaging densitometer (Bio-Rad Laboratories, Hercules, CA, USA) and analyzed using Labworks 4.0 software.

\subsection{Psoriasis Mouse Model}

All animals were housed in an animal room under temperature control $\left(24-25^{\circ} \mathrm{C}\right)$ and a $12: 12 \mathrm{~h}$ light-dark cycle. Standard laboratory chow and tap water were available ad libitum. Experimental procedures were approved by the Mackay Memorial Hospital Review Board (New Taipei City, Taiwan) (project code: MMH-A-S-104-37, date: 1 January 2016-31 December 2018) and were performed in compliance with national animal welfare regulations (Council of Agriculture, R.O.C).

$\mathrm{BALB} / \mathrm{c}$ mice (8-week-old females) were shaved on the back and psoriasis was induced by topical application of with IMQ cream, as described previously [17]. Accordingly, each mouse received a daily topical dose of $62.5 \mathrm{mg}$ of commercially available IMQ cream (5\%; Aldara; 3M Pharmaceuticals) on the shaved back, and $15 \mathrm{mg}$ of IMQ on the right ear, for 6 consecutive days. Control mice (normal group) were treated with a control cream. For treatment, $25 \mu \mathrm{M}$ C16 or dimethyl sulfoxide (DMSO as peptide vehicle) was mixed with the IMQ cream. Histologic analysis of back skin specimens was performed just after the termination of IMQ application (on day 7). Ear thickness was measured in duplicate using a digital micrometer before challenge and after IMQ treatment for 6 consecutive days.

\subsection{Histopathological Examination}

Formalin-fixed samples from the middle of the back skin were embedded in paraffin, sectioned $(5 \mu \mathrm{m})$, and stained with hematoxylin-eosin. Images were captured using a Nikon Eclipse 80i microscope (Nikon Corporation, Tokyo, Japan) equipped with a Leica DC 500 camera (Leica Microsystems, Wetzlar, Germany). At least six different sections were examined per skin sample. The epidermal thickness was quantified from the photographs using a computer-assisted image analyzer (Adobe Photoshop CS3 10.0).

\subsection{In Vivo Detection of DNA Synthesis}

To measure cell proliferation, BrdU was used after reconstitution in DMSO at (80 mM). Of this BrdU stock, $15 \mu \mathrm{L}$ was mixed with $90 \mu \mathrm{L}$ PBS and injected intraperitoneally into the mice at $24 \mathrm{~h}$ prior to euthanasia with $\mathrm{CO}_{2}$. Formalin-fixed, paraffin-embedded skin specimens were deparaffinized in xylene and rehydrated in a graded series of ethanol concentrations. Slides were treated with $1 \mathrm{~N} \mathrm{HCl}$ at RT for $1 \mathrm{~h}$ before immunohistochemistry. The slides were blocked with $10 \%$ goat serum for $60 \mathrm{~min}$ and then incubated with primary antibody against $\mathrm{BrdU}\left(1: 100\right.$ dilution) at $37^{\circ} \mathrm{C}$ for $3 \mathrm{~h}$. The slides were subsequently incubated with peroxidase-labeled goat immunoglobulin (1:500 dilution; Chemicon, Temecula, CA, USA) for $20 \mathrm{~min}$ and then incubated with chromogen substrate (3,3'-diaminobenzidine) for 2 min before counterstaining with hematoxylin.

\subsection{Immunofluorescence}

Deparaffinized tissue sections or 4\% paraformaldehyde-fixed HaCat cells were blocked with $10 \%$ goat serum and 5\% bovine serum albumin (BSA) in PBS containing $0.5 \%$ Triton X-100 (PBST) for $20 \mathrm{~min}$. Staining was performed using primary antibodies against FAK (1:100 dilution), fibronectin (1:100 dilution), Ly6g (1:100 dilution), or F4/80 (1:100 dilution) at $37^{\circ} \mathrm{C}$ for $3 \mathrm{~h}$. For staining of integrin $\alpha 5$ and $\beta 1$ (1:100 dilution), sections were stained at $4{ }^{\circ} \mathrm{C}$ for overnight. The slides were subsequently incubated with the appropriate fluorescent-labeled secondary antibodies (1:500 dilution) at $37^{\circ} \mathrm{C}$ for $1 \mathrm{~h}$ and then 
counterstained with Hoechst 33258 for 6 min. The slide was also stained F-actin by TRITC-phalloidin $(25 \mu \mathrm{g} / \mathrm{mL})$ at $37^{\circ} \mathrm{C}$ for $1 \mathrm{~h}$. The slides were then rinsed with PBST three times, mounted with FluorSave ${ }^{\mathrm{TM}}$ reagent (Calbiochem, La Jolla, CA, USA), and viewed with an epifluorescence microscope (Zeiss Axioplan 2 imaging; Zeiss, Oberkochen, Germany) equipped with a charge-coupled device camera (Zeiss AxioCam HRm, Zeiss) and quantification was performed using Axiovert software (Zeiss AxioVision Release 4.8.2, Zeiss).

\subsection{Quantitative Real-Time RT-PCR}

The total RNA extraction, cDNA synthesis, and real-time PCR were performed as described previously [56]. Primers used in the experiment are listed in Table 1.

Table 1. Primers used in the real-time qPCR.

\begin{tabular}{ccc}
\hline Target Gene & Primer (Sense) & Primer (Antisense) \\
\hline mIL-17A & $5^{\prime}$-CTGCTGAGCCTGGCGGCTAC-3' & $5^{\prime}$-CATTGCGGTGGAGAGTCCAGGG-3' \\
mIL-22 & $5^{\prime}$-CAGCTCCTGTCACATCAGCGGT-3' & $5^{\prime}$-AGGTCCAGTTCCCCAATCGCCT-3' \\
mIL-23 & $5^{\prime}$-TCCTCCAGCCAGAGGATCACCC-3' & $5^{\prime}$-AGAGTTGCTGCTCCGTGGGC-3' \\
mTNF- $\alpha$ & $5^{\prime}$-GCCCACGTCGTAGCAAACCAC-3' & $5^{\prime}$-GCAGGGGCTCTTGACGGCAG-3' \\
mIL-1 $\beta$ & $5^{\prime}$-CCCTGCAGCTGGAGAGTGTGGA-3' & $5^{\prime}$-TGTGCTCTGCTTGTGAGGTGCTG-3' \\
mIL-6 & $5^{\prime}$-CCTCTCTGCAAGAGACTTCCAT-3' & $5^{\prime}$-AGTCTCCTCTCCGGACTTGT-3'3 \\
mCXCL1 & $5^{\prime}$-ACCGAAGTCATAGCCACACT-3' & $5^{\prime}$-CTGAACCAAGGGAGCTTCA-3' \\
mCXCL2 & $5^{\prime}$-TCCCTCAACGGAAGAACCAA-3' & $5^{\prime}$-AGGCACATCAGGTACGATCC-3' \\
mCCL3 & $5^{\prime}$-ACATCATGAAGGTCTCCACCA-3' & $5^{\prime}$-TCCATATGGCGCTGAGAAGA-3' \\
mCCL4 & 5'-AAGCCAGCTGTGGTATTCCT-3' & $5^{\prime}$-CTCTCCTGAAGTGGCTCCTC-3' \\
mGAPDH & $5^{\prime}$-GGGCTCTCTGCTCCTCCCTGT-3' & $5^{\prime}$-CGGCCAAATCCGTTCACACCG-3' \\
hTNF- $\alpha$ & $5^{\prime}$-AGGACCAGCTAAGAGGGAGA-3' & $5^{\prime}$-TTCAGTGCTCATGGTGTCCT-3' \\
hGAPDH & $5^{\prime}$-ACCCAGAAGACTGTGGATGG-3' & $5^{\prime}$-TCAGCTCAGGGATGACCTTG-3' \\
\hline
\end{tabular}

\subsection{Statistics}

The data were generated from three independent experiments. All numerical values are expressed as the mean \pm SD. Comparisons of two groups were made using the Mann-Whitney test. $p<0.05$ was considered significant.

\section{Conclusion}

In conclusion, our data suggest that $\mathrm{C} 16$ peptide might act as an $\alpha 5 \beta 1$ integrin antagonist to attenuate the early onset inflammatory responses in psoriasis-like skin disease. Further explorations of the expression of $\alpha 5 \beta 1$ and $\alpha \mathrm{v} \beta 3$ in the inflammatory progression of psoriasis and establishment of in vitro models for research into the effect of C16 on immune cells are important to further support the integrins as important targets for psoriasis therapy.

Author Contributions: T.-C.H. designed the experiments, performed the experiments, and wrote the paper; S.-I.Y. and S.-L.C. designed the experiments and performed the experiments; Y.-P.T. designed the experiments and analyzed the data. All authors reviewed and approved the final version of the manuscript.

Funding: The funding support from the Ministry of Science and Technology, Taiwan (MOST 104-2314-B-195-006-MY3) and Mackay Memorial Hospital (MMH-E-108-006).

Acknowledgments: We thank Tim J Harrison for kindly reading this manuscript. The authors would like to acknowledge Chu-Ping Ho and Yi-Cheng Huang for their assistance with sample collection and histological preparations.

Conflicts of Interest: The authors declare no conflict of interest. 


\section{References}

1. Di Cesare, A.; Di Meglio, P.; Nestle, F. The IL-23/Th17 axis in the immunopathogenesis of psoriasis. J. Invest. Dermatol. 2009, 129, 1339-1350. [CrossRef] [PubMed]

2. Van Bell, A.B.; de Heusch, M.; Lemaire, M.M.; Hendrickx, E.; Warnier, G.; Dunussi-Joannopoulos, K.; Fouser, L.A.; Renauld, J.C.; Dumoutier, L. IL-22 is required for imiquimod-induced psoriasiform skin inflammation in mice. J. Immunol. 2012, 188, 462-469. [CrossRef] [PubMed]

3. Humphries, J.D.; Chastney, M.R.; Askari, J.A.; Humphries, M.J. Signal transduction via integrin adhesion complexes. Curr. Opin. Cell Biol. 2019, 56, 14-21. [CrossRef] [PubMed]

4. Pellegrini, G.; De, L.M.; Orecchia, G.; Balzac, F.; Cremona, O.; Savoia, P.; Cancedda, R.; Marchisio, P.C. Expression, topography, and function of integrin receptors are severely altered in keratinocytes from involved and uninvolved psoriatic skin. J. Clin. Invest. 1992, 89, 1783-1795. [CrossRef] [PubMed]

5. Bata-Csorgo, Z.; Cooper, K.D.; Ting, K.M.; Voorhees, J.J.; Hammerberg, C. Fibronectin and alpha5 integrin regulate keratinocyte cell cycling. A mechanism for increased fibronectin potentiation of $\mathrm{T}$ cell lymphokine-driven keratinocyte hyperproliferation in psoriasis. J. Clin. Invest. 1998, 101, 1509-1518. [CrossRef] [PubMed]

6. Gubán, B.; Vas, K.; Balog, Z.; Manczinger, M.; Bebes, A.; Groma, G.; Széll, M.; Kemény, L.; Bata-Csörgő, Z. Abnormal regulation of fibronectin production by fibroblasts in psoriasis. Br. J. Dermatol. 2016, 174, 533-541. [CrossRef]

7. Carroll, J.M.; Romero, M.R.; Watt, F.M. Suprabasal integrin expression in the epidermis of transgenic mice results in developmental defects and a phenotype resembling psoriasis. Cell 1995, 83, 957-968. [CrossRef]

8. Yang, J.T.; Hynes, R.O. Fibronectin receptor functions in embryonic cells deficient in alpha 5 beta 1 integrin can be replaced by alpha V integrins. Mol. Biol. Cell 1996, 7, 1737-1748. [CrossRef]

9. Kim, S.; Bell, K.; Mousa, S.A.; Varner, J.A. Regulation of angiogenesis in vivo by ligation of integrin alpha5beta1 with the central cell-binding domain of fibronectin. Am. J. Pathol. 2000, 156, 1345-1362. [CrossRef]

10. Cai, W.J.; Li, M.B.; Wu, X.; Wu, S.; Zhu, W.; Chen, D.; Luo, M.; Eitenmüller, I.; Kampmann, A.; Schaper, J.; et al. Activation of the integrins alpha 5 beta 1 and alpha $v$ beta 3 and focal adhesion kinase (FAK) during arteriogenesis. Mol. Cell. Biochem. 2009, 322, 161-169. [CrossRef]

11. Ponce, M.L.; Nomizu, M.; Delgado, M.C.; Kuratomi, Y.; Hoffman, M.P.; Powell, S.; Yamada, Y.; Kleinman, H.K.; Malinda, K.M. Identification of endothelial cell binding sites on the laminin gamma 1 chain. Circ. Res. 1999, 84, 688-694. [CrossRef] [PubMed]

12. Ponce, M.L.; Nomizu, M.; Kleinman, H.K. An angiogenic laminin site and its antagonist bind through the alpha(v)beta3 and alpha5beta1 integrins. FASEB J. 2001, 15, 1389-1397. [CrossRef] [PubMed]

13. Fang, M.; He, D.; Zhang, F.; Hu, Z.; Yang, J.; Jiang, H.; Han, S. Antineuroinflammatory and neurotrophic effects of CNTF and C16 peptide in an acute experimental autoimmune encephalomyelitis rat model. Front. Neuroanat. 2013, 7, 44. [CrossRef] [PubMed]

14. Han, S.; Zhang, F.; Hu, Z.; Sun, Y.; Yang, J.; Davies, H.; Yew, D.T.; Fang, M. Dose-dependent anti-inflammatory and neuroprotective effects of an $\alpha v \beta 3$ integrin-binding peptide. Mediators Inflamm. 2013, 268486.

15. Tian, K.W.; Zhang, Y.Y.; Jiang, H.; Han, S. Intravenous C16 and angiopoietin-1 improve the efficacy of placenta-derived mesenchymal stem cell therapy for EAE. Sci. Rep. 2018, 8, 4649. [CrossRef]

16. Gilliet, M.; Conrad, C.; Geiges, M.; Cozzio, A.; Thürlimann, W.; Burg, G.; Nestle, F.O.; Dummer, R. Psoriasis triggered by toll-like receptor 7 agonist imiquimod in the presence of dermal plasmacytoid dendritic cell precursors. Arch. Dermatol. 2004, 140, 1490-1495. [CrossRef]

17. Van der Fits, L.; Mourits, S.; Voerman, J.S.; Kant, M.; Boon, L.; Laman, J.D.; Cornelissen, F.; Mus, A.M.; Florencia, E.; Prens, E.P.; et al. Imiquimod-induced psoriasis-like skin inflammation in mice is mediated via the IL-23/IL-17 axis. J. Immunol. 2009, 182, 5836-5845. [CrossRef]

18. Széll, M.; Bata-Csörgo, Z.; Koreck, A.; Pivarcsi, A.; Polyánka, H.; Szeg, C.; Gaál, M.; Dobozy, A.; Kemény, L. Proliferating keratinocytes are putative sources of the psoriasis susceptibility-related EDA+ (extra domain A of fibronectin) oncofetal fibronectin. J. Invest. Dermatol. 2004, 123, 537-546. [CrossRef]

19. Pivarcsi, A.; Széll, M.; Kemény, L.; Dobozy, A.; Bata-Csörgo, Z. Serum factors regulate the expression of the proliferation-related genes alpha5 integrin and keratin 1, but not keratin 10, in HaCaT keratinocytes. Arch Dermatol. Res. 2001, 293, 206-213. [CrossRef] 
20. Grzesiak, J.J.; Pierschbacher, M.D. Changes in the concentrations of extracellular $\mathrm{Mg}++$ and $\mathrm{Ca}++$ down-regulate E-cadherin and up-regulate alpha 2 beta 1 integrin function, activating keratinocyte migration on type I collagen. J. Invest. Dermatol. 1995, 104, 768-774. [CrossRef]

21. Klein, S.; de Fougerolles, A.R.; Blaikie, P.; Khan, L.; Pepe, A.; Green, C.D.; Koteliansky, V.; Giancotti, F.G. Alpha 5 beta 1 integrin activates an NF-kappa B-dependent program of gene expression important for angiogenesis and inflammation. Mol. Cell. Biol. 2002, 22, 5912-5922. [CrossRef]

22. Albanesi, C.; Madonna, S.; Gisondi, P.; Girolomoni, G. The Interplay between Keratinocytes and Immune Cells in the Pathogenesis of Psoriasis. Front. Immunol. 2018, 6, 1549. [CrossRef]

23. Zeng, Z.Z.; Jia, Y.; Hahn, N.J.; Markwart, S.M.; Rockwood, K.F.; Livant, D.L. Role of focal adhesion kinase and phosphatidylinositol 3'-kinase in integrin fibronectin receptor-mediated, matrix metalloproteinase-1-dependent invasion by metastatic prostate cancer cells. Cancer Res. 2006, 66, 8091-8099. [CrossRef]

24. Schaller, M.D.; Hildebrand, J.D.; Shannon, J.D.; Fox, J.W.; Vines, R.R.; Parsons, J.T. Autophosphorylation of the focal adhesion kinase, pp125FAK, directs SH2-dependent binding of pp60src. Mol. Cell. Biol. 1994, 14, 1680-1688. [CrossRef]

25. Tamura, M.; Gu, J.; Tran, H.; Yamada, K.M. PTEN gene and integrin signaling in cancer. J. Natl. Cancer Inst. 1999, 91, 1820-1828. [CrossRef]

26. Reif, S.; Lang, A.; Lindquist, J.N.; Yata, Y.; Gabele, E.; Scanga, A.; Brenner, D.A.; Rippe, R.A. The role of focal adhesion kinase-phosphatidylinositol 3-kinase-akt signaling in hepatic stellate cell proliferation and type I collagen expression. J. Biol. Chem. 2003, 278, 8083-8090. [CrossRef]

27. Raghavan, S.; Bauer, C.; Mundschau, G.; Li, Q.; Fuchs, E. Conditional ablation of beta1 integrin in skin. Severe defects in epidermal proliferation, basement membrane formation, and hair follicle invagination. J. Cell Biol. 2000, 150, 1149-1160. [CrossRef]

28. Brakebusch, C.; Grose, R.; Quondamatteo, F.; Ramirez, A.; Jorcano, J.L.; Pirro, A.; Svensson, M.; Herken, R.; Sasaki, T.; Timpl, R.; et al. Skin and hair follicle integrity is crucially dependent on beta 1 integrin expression on keratinocytes. EMBO J. 2000, 19, 3990-4003. [CrossRef]

29. Wennerberg, K.; Lohikangas, L.; Gullberg, D.; Pfaff, M.; Johansson, S.; Fässler, R. Beta 1 integrin-dependent and -independent polymerization of fibronectin. J. Cell Biol. 1996, 132, 227-238. [CrossRef]

30. Senra, L.; Stalder, R.; Alvarez, M.D.; Chizzolini, C.; Boehncke, W.H.; Brembilla, N.C. Keratinocyte-Derived IL-17E Contributes to Inflammation in Psoriasis. J. Invest. Dermatol. 2016, 136, 1970-1980. [CrossRef]

31. Chiricozzi, A.; Romanelli, P.; Volpe, E.; Borsellino, G.; Romanelli, M. Scanning the Immunopathogenesis of Psoriasis. Int. J. Mol. Sci. 2018, 19, 179. [CrossRef]

32. Pedrosa, E.; Carretero-Iglesia, L.; Boada, A.; Colobran, R.; Faner, R.; Pujol-Autonell, I.; Palou, E.; Esteve, A.; Pujol-Borrell, R.; Ferrándiz, C.; et al. CCL4L polymorphisms and CCL4/CCL4L serum levels are associated with psoriasis severity. J. Invest. Dermatol. 2011, 131, 1830-1837. [CrossRef]

33. De Filippo, K.; Dudeck, A.; Hasenberg, M.; Nye, E.; van Rooijen, N.; Hartmann, K.; Gunzer, M.; Roers, A.; Hogg, N. Mast cell and macrophage chemokines CXCL1/CXCL2 control the early stage of neutrophil recruitment during tissue inflammation. Blood 2013, 121, 4930-4937. [CrossRef]

34. Ting, K.M.; Rothaupt, D.; McCormick, T.S.; Hammerberg, C.; Chen, G.; Gilliam, A.C.; Stevens, S.; Culp, L.; Cooper, K.D. Overexpression of the oncofetal Fn variant containing the EDA splice-in segment in the dermal-epidermal junction of psoriatic uninvolved skin. J. Invest. Dermatol. 2000, 114, 706-711. [CrossRef]

35. Yost, J.; Gudjonsson, J.E. The role of TNF inhibitors in psoriasis therapy: New implications for associated comorbidities. F1000 Med. Rep. 2009, 8, 1. [CrossRef]

36. Jiang, M.; Qiu, J.; Zhang, L.; Lü, D.; Long, M.; Chen, L.; Luo, X. Changes in tension regulates proliferation and migration of fibroblasts by remodeling expression of ECM proteins. Exp. Ther. Med. 2016, 12, 1542-1550. [CrossRef]

37. Tamura, K.; Okazaki, M.; Tamura, M.; Kanegae, K.; Okuda, H.; Abe, H.; Nakashima, Y. Synergistic interaction of integrin and angiotensin II in activation of extracellular signal-regulated kinase pathways in vascular smooth muscle cells. J Cardiovasc. Pharmacol. 2001, 38, S59-S62. [CrossRef]

38. Kanegae, K.; Tamura, M.; Kabashima, N.; Serino, R.; Tokunaga, M.; Oikawa, S.; Nakashima, Y. Synergistic induction of monocyte chemoattractant protein-1 by integrins and platelet-derived growth factor via focal adhesion kinase in mesangial cells. Nephrol. Dial. Transplant. 2005, 20, 2080-2088. [CrossRef] 
39. Higuchi, M.; Kihara, R.; Okazaki, T.; Aoki, I.; Suetsugu, S.; Gotoh, Y. Akt1 promotes focal adhesion disassembly and cell motility through phosphorylation of FAK in growth factor-stimulated cells. J. Cell Sci. 2013, 126, 745-755. [CrossRef]

40. Moreno-Layseca, P.; Streuli, C.H. Signalling pathways linking integrins with cell cycle progression. Matrix Biol. 2014, 34, 144-153. [CrossRef]

41. Turecková, J.; Vojtechová, M.; Krausová, M.; Sloncová, E.; Korínek, V. Focal adhesion kinase functions as an akt downstream target in migration of colorectal cancer cells. Transl. Oncol. 2009, 2, 281-290. [CrossRef]

42. Woodard, A.S.; García-Cardeña, G.; Leong, M.; Madri, J.A.; Sessa, W.C.; Languino, L.R. The synergistic activity of alphavbeta3 integrin and PDGF receptor increases cell migration. J. Cell Sci. 1998, 111, 469-478.

43. Lai, Y.; Li, D.; Li, C.; Muehleisen, B.; Radek, K.A.; Park, H.J.; Jiang, Z.; Li, Z.; Lei, H.; Quan, Y.; et al. The antimicrobial protein REG3A regulates keratinocyte proliferation and differentiation after skin injury. Immunity 2012, 37, 74-84. [CrossRef]

44. Mitra, A.; Raychaudhuri, S.K.; Raychaudhuri, S.P. IL-22 induced cell proliferation is regulated by $\mathrm{PI} 3 \mathrm{~K} / \mathrm{Akt} / \mathrm{mTOR}$ signaling cascade. Cytokine 2012, 60, 38-42. [CrossRef]

45. Lishko, V.K.; Yakubenko, V.P.; Ugarova, T.P. The interplay between integrins alphaMbeta2 and alpha5beta1 during cell migration to fibronectin. Exp. Cell. Res. 2003, 283, 116-126. [CrossRef]

46. Lv, P.C.; Jiang, A.Q.; Zhang, W.M.; Zhu, H.L. FAK inhibitors in Cancer, a patent review. Expert Opin. Ther. Pat. 2018, 28, 139-145. [CrossRef]

47. Böckmann, S.; Seep, J.; Jonas, L. Delay of neutrophil apoptosis by the neuropeptide substance P: Involvement of caspase cascade. Peptides 2001, 22, 661-670. [CrossRef]

48. Kubo, M.; Clark, R.A.; Katz, A.B.; Taichman, L.B.; Jin, Z.; Zhao, Y.; Moriguchi, T. Transduction of beta3 integrin subunit cDNA confers on human keratinocytes the ability to adhere to gelatin. Arch. Dermatol. Res. 2007, 299, 13-24. [CrossRef]

49. Antonov, A.S.; Antonova, G.N.; Munn, D.H.; Mivechi, N.; Lucas, R.; Catravas, J.D.; Verin, A.D. $\alpha$ V $\beta 3$ integrin regulates macrophage inflammatory responses via PI3 kinase/Akt-dependent NF-kB activation. J. Cell. Physiol. 2011, 226, 469-476. [CrossRef]

50. Schön, M.P.; Erpenbeck, L. The Interleukin-23/Interleukin-17 Axis Links Adaptive and Innate Immunity in Psoriasis. Front. Immunol. 2018, 15, 1323. [CrossRef]

51. Cather, J.C.; Crowley, J.J. Use of biologic agents in combination with other therapies for the treatment of psoriasis. Am. J. Clin. Dermatol. 2014, 15, 467-478. [CrossRef]

52. Feldman, S.R.; Goffe, B.; Rice, G.; Mitchell, M.; Kaur, M.; Robertson, D.; Sierka, D.; Bourret, J.A.; Evans, T.S.; Gottlieb, A. The Challenge of Managing Psoriasis: Unmet Medical Needs and Stakeholder Perspectives. Am. Health Drug Benefits 2016, 9, 504-513.

53. Kirkham, B.W.; Kavanaugh, A.; Reich, K. Interleukin-17A: A unique pathway in immune-mediated diseases: Psoriasis, psoriatic arthritis and rheumatoid arthritis. Immunology 2014, 141, 133-142. [CrossRef]

54. Beyaert, R.; Beaugerie, L.; Van Assche, G.; Brochez, L.; Renauld, J.C.; Viguier, M.; Cocquyt, V.; Jerusalem, G.; Machiels, J.P.; Prenen, H.; et al. Cancer risk in immune-mediated inflammatory diseases (IMID). Mol. Cancer 2013, 12, 98. [CrossRef]

55. Semba, C.P.; Gadek, T.R. Development of lifitegrast: A novel T-cell inhibitor for the treatment of dry eye disease. Clin. Ophthalmol. 2016, 10, 1083-1094. [CrossRef]

56. Shih, S.C.; Ho, T.C.; Chen, S.L.; Tsao, Y.P. Pigment epithelium-derived factor (PEDF) peptide promotes the expansion of hepatic stem/progenitor cells via ERK and STAT3-dependent signaling. Am. J. Transl. Res. 2017, 9, 1114-1126.

(C) 2019 by the authors. Licensee MDPI, Basel, Switzerland. This article is an open access article distributed under the terms and conditions of the Creative Commons Attribution (CC BY) license (http://creativecommons.org/licenses/by/4.0/). 